\title{
Cranberry Stomatal Conductivity
}

\author{
Paul J. Croft, Mark D. Shulman, and Roni Avissar \\ Department of Meteorology, Cook College, Rutgers University, P.O. Box 231, \\ New Brunswick, NJ 08903-0231
}

Additional index words. Ericaceae, stress, Vaccinium macrocarpon, xeromorphy

\begin{abstract}
Cranberry (Vaccinium macrocarpon Ericaceae Ait.) stomatal conductivity (SC) was investigated in the field to examine plant response as a function of weather conditions. Measurements were made during fruit maturation on 14 days between 0540 and $1710 \mathrm{HR}$, as weather conditions permitted. SC ranged from 0.02 to $0.08 \mathrm{~cm} \cdot \mathrm{s}^{-1}$ and was much lower than for most other crops. Scatter plots of SC vs. leaf temperature by day indicated only a weak linear relationship. When the data were stratified by time of day and by clear and overcast skies, several significant Pearson correlation coefficients suggested a stomatal response. The findings, when combined with current knowledge of the physical structure of cranberry stomata, suggest that cranberries behave as xeromorphic plants.
\end{abstract}

The stomatal response of the cranberry plant is not well known. As a result, water management decisions, pesticide applications, and many cultural practices are instituted based on an incomplete knowledge of the cranberry water regime. The activity and characteristics of cranberry stomata were explored first by Sawyer (1932) on 'Early Black', 'Pride', 'McFarlin', and 'Howes' cranberry. The number of stomata per square millimeter of leaf surface area (mean, 632) was much higher than that for other plants. The stomata, located on the abaxial surface of the leaf, were slitlike. Under identical field conditions, Sawyer found that stomata for different cultivars and on the same leaf seemed to behave independently and had a high degree of cutinization in the leaves and cells. Sawyer theorized that the stomata were closing by midday and not adjusting, or responding very slowly, to changing light, temperature, and moisture conditions.

Faraq and Palta (1989) more recently examined the surface morphology and ultrastructure of 'Searles' cranberries with regard to chemical penetration. They observed that the leaf surface has no trichomes and has a thick, continuous layer of epicutictrlar wax. Stomata are found only on the abaxial surface in a parallel and alternating pattern; they are coated with wax, sunken, and covered by an inner cuticular sheath. These leaf characteristics resemble those of a desert plant and indicate xeromorphy, which would restrict chemical penetration and water loss severely and afford a high level of drought tolerance.

The objective of this investigation was to determine the nature and significance of in situ cranberry stomatal conductivity (SC) to ex-

\footnotetext{
Received for publication 4 Dec. 1992. Accepted for publication 8 June 1993. This work was performed as part of the New Jersey Agricultural Experiment Station projects D-13201-1-92 and 13105 and was supported in part by Hatch Act funds. Additional support was provided by Ocean Spray. We thank Paul Eck for his suggestions and comments. The cost of publishing this paper was defrayed in part by the payment of page charges. Under postal regulations, this paper therefore must be hereby marked advertisement solely to indicate this fact.
}

amine plant response as a function of weather conditions. For this purpose, a field experiment was carried out from July to Oct. 1990 at a cranberry research bog at the Rutgers Univ. Blueberry and Cranberry Research Center (RUBCRC), Chatsworth, N.J. 'Early Black' cranberry SC, leaf temperature, and photosynthetically active radiation were measured with a steady-state porometer (model LI-1600; LICOR, Lincoln, Neb.). The bog is $110 \times 17 \mathrm{~m}$ and is oriented from southeast to northwest. The bog is separated from other research bogs by a dike and ditch bank. The dike and ditch bank is $\approx 7 \mathrm{~m}$ across, and each ditch is $\approx 1 \mathrm{~m}$ across.

The cranberry plants in the bog form a mesh of vines that completely cover the ground's surface and form a plant layer $=15$ $\mathrm{cm}$ thick. The soil may consist of pure sand, peat, or both and most often is a loamy sand. Cranberry plants are surrounded by a moat, with water levels typically maintained at 45 $\mathrm{cm}$ below the bog soil surface. However, since water levels may vary considerably with weather and field conditions, occasionally they were raised or lowered by RUBCRC staff to approximate a status quo. Overhead irrigation was applied at times to the ends of the bog and to adjacent research bogs, although no irrigation was used in the middle of the bog where measurements were made. A thin layer of sand is applied to the bog at the beginning of each growing season.

Cranberry leaves in the canopy and within $2.5 \mathrm{~cm}$ of the tip of uprights were selected for study and were $\approx 2$ months old at the beginning of the experiment and 2 months older at its completion. Since the cranberry leaf is small, a cylindrical chamber attachment must be used with the porometer to determine SC. When using this chamber, many leaflets must be sampled simultaneously and SC measurements must be weighted by the ratio of the sample leaf area enclosed to the standard aperture setting of the porometer. SC was measured in leaves near the stem tip of fruiting uprights; to do this required that part of the stem be enclosed in the porometer. However, the size and thickness of the stem relative to leaf area was negligible. Based on plant samples routinely cut before and during field measurements, we determined that a leaf area of $90 \mathrm{~cm}^{2}$ typically was enclosed during sampling.

$\mathrm{SC}$ was measured on 14 days between 0540 and $1710 \mathrm{HR}$, as conditions permitted. SC was not measured when leaves were wet from dew or rain, but had to be measured during fruit ripening so that we could determine the final yield midway between the bog's center and its southern edge. Since SC was measured in the canopy, interference from other leaves made it impossible to expose the radiation sensor properly; thus, these readings were not used. Measurements were classified as morning (0600 to $1000 \mathrm{HR}$ ), midday (1000 to 1400 $\mathrm{HR}$ ), and afternoon (1400 to $1800 \mathrm{HR}$ ) to characterize the nature of cranberry stomatal response. Observations were made under clear and overcast skies to determine differences in stomatal activity under varying weather conditions.

Cranberry SC covered a narrow range $\left(0.02-0.08 \mathrm{~cm} \cdot \mathrm{s}^{-1}\right)$, with a mean value of 0.05 $\mathrm{cm} \cdot \mathrm{s}^{-1}$ (Table 1). Compared to the SC of other plants, cranberry SC, as measured here, was extremely small. Avissar (1993), Holmgren et al. (1965), and Rochette et al. (1991) indicate that SC for most crops is from 0.10 to $1.0 \mathrm{~cm} \cdot \mathrm{s}^{-1}$ under typical field conditions. We believe that the measurements were realistic, given the physical structure of cranberry stomata as determined by Faraq and Palta (1989) and despite concerns raised by Idso et al. (1988) on the use of porometry. Although Meyer et al. (1985) stated that porometer-derived leaf stomatal conductance and resistance "must be regarded as qualitative only," Monteith (1990) and Turner (1991) indicated that systematic errors of porometry are avoidable and correctable.

Scatter plots of leaf temperature and SC for individual days (e.g., Fig. 1a, 2 Aug.) show a weak linear relationship, which is obfuscated when all days are examined, between temperature and stomatal response (Fig. 1d). When data were stratified by clear vs. overcast days (Fig. $1 \mathrm{~b}$ and c, respectively), and according to the time of day, a more definitive pattern was evident. Clear days had no clouds or had scattered cloud coverage (no more than half of the sky covered by clouds) and overcast days had broken clouds or the sky was more than half covered by clouds. Thus, there was a weak inverse linear relationship between SC and leaf temperature on clear days (Fig. 1b). The clustering of SC readings at higher temperatures on overcast days (Fig. 1c) is coincidental, as most of these observations were made during midday (Table 1), when canopy temperatures were at their peak.

To assess the relationship between SC and other variables, Pearson correlation coefficients were calculated (Table 1). On some days, leaf temperature and time each correlated with SC at $P \leq 0.05$ or higher. When all observations were considered, leaf temperature and time correlated significantly with SC, although some coefficients were extremely low. Data stratified according to time of day indicated that leaf temperature and SC correlated significantly during midday and afternoon. 
Table 1. Dates and times of stomatal conductivity (SC) measurements made during the 1990 growing season. Maximum, minimum, and mean SCs are given for each day, for various subsets, and the total number of observations.

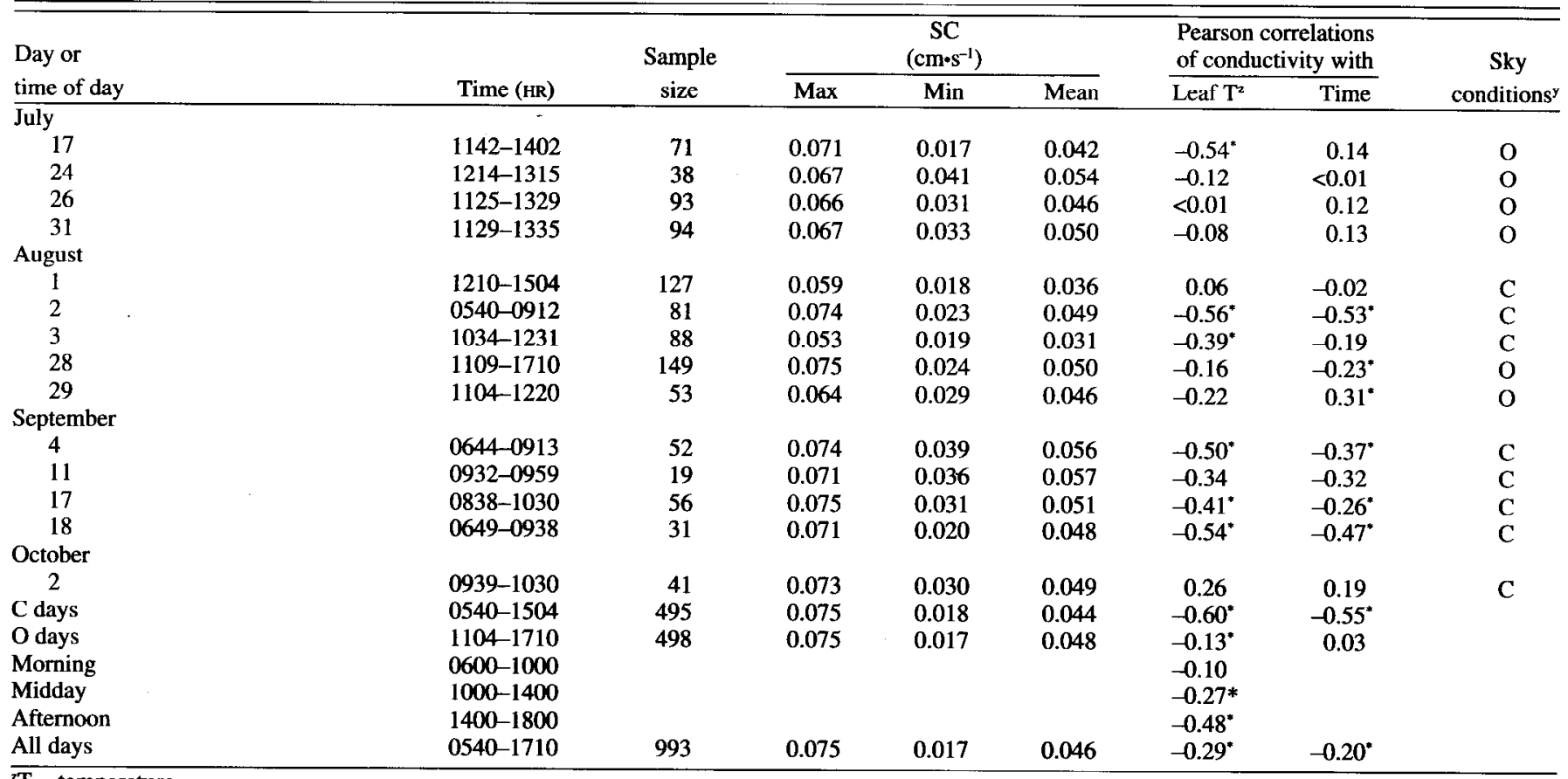

${ }^{2} \mathrm{~T}=$ temperature.

${ }^{\text {y }} \mathrm{O}=$ overcast $; \mathrm{C}=$ clear.

*Significant at $P \leq 0.05$.

2 August 1990

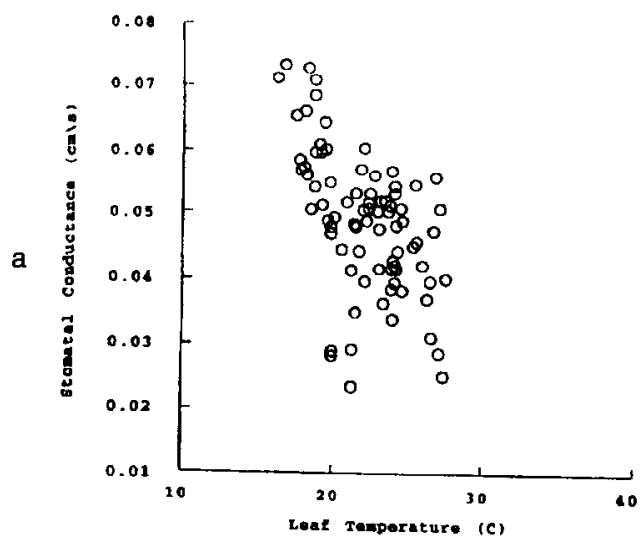

Overcast Days

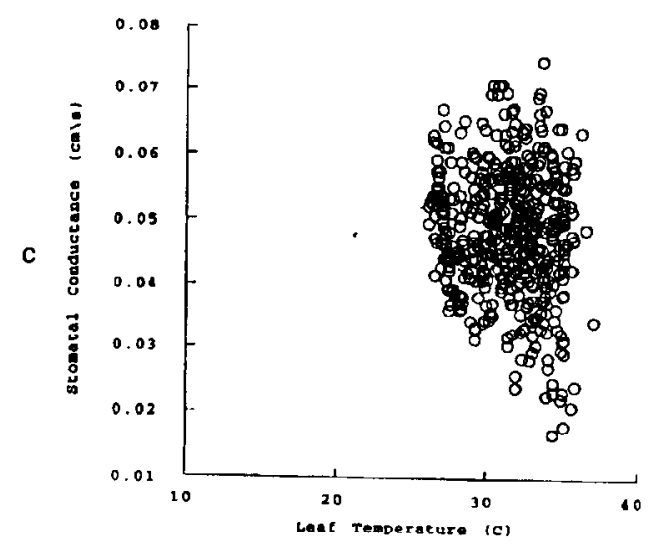

Clear Days

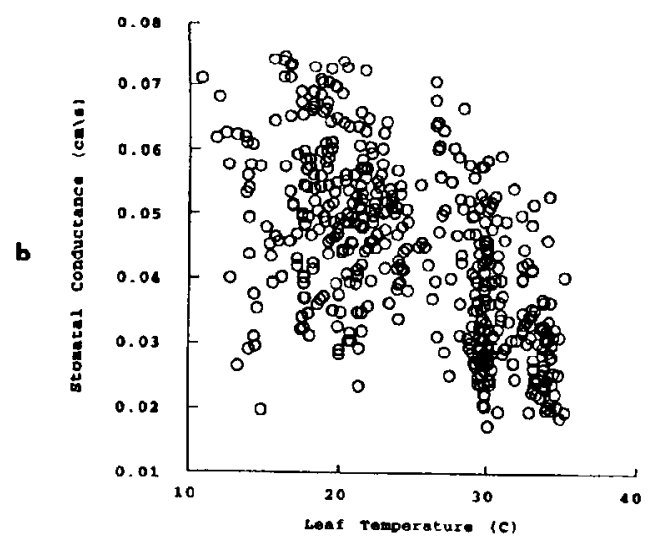

All Days

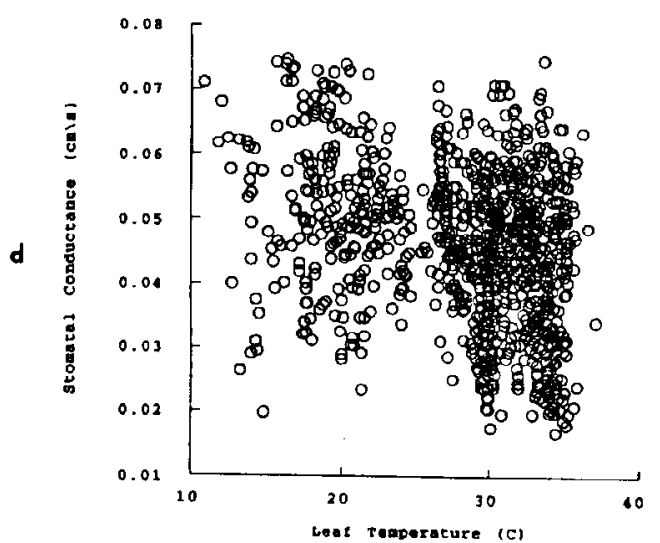

Fig. 1. Scatter plot of leaf temperature $\left({ }^{\circ} \mathrm{C}\right)$ vs. stomatal conductivity (in centimeters per second) for observations on (a) 2 Aug., a clear day; (b) all clear days; (c) all overcast days; and (d) all days combined. 
SC histograms were generated across the entire data and for subsets (Fig. 2). The histogram for all data (Fig. 2a) indicated a nearly normal SC distribution, with only slight skewness (-0.079) and some "flatness" (kurtosis of -0.491 ) in response across a wide range of weather conditions. The mean leaf temperature across all observations was 28.3C. In contrast, the histogram for the subset of clearday data (Fig. 2b) exhibited positive skew $(0.222)$ and a marked "even" flat response (kurtosis of -0.814). On clear days, the mean leaf temperature was $25.2 \mathrm{C}$, and SC was concentrated more frequently and more uniformly across lower values. SC distribution for overcast days (Fig. 2c) indicated a prevalence of higher values (skew of-0.2 15 and kurtosis of 0.194 ) combined with a higher mean leaf temperature (31.4C). Positive kurtosis indicates a tendency of the SC to behave more uniformly (i.e., less variability in the canopy). Statistical testing indicates that data for overcast days were distributed normally. Similar analyses by time of day revealed that, although morning (0600 to $1000 \mathrm{HR}$ ) and afternoon (1400 to $1800 \mathrm{HR}$ ) observations had negative skew, only morning observations fit a normal distribution.

The limited range of cranberry SC and the inconsistent nature of plant response from day to day suggests that the cranberry plant exhibits xeromorphic characteristics. However, when the data are stratified, changes in cranberry $\mathrm{SC}$, as related to leaf temperature, indicate that SC is restricted on clear days and during midday and afternoon. The negative skew and greater frequency of higher values exhibited in the SC distribution on overcast days and during morning indicate a limited environmental response. These observations suggest that, because of their physical attributes, cranberry stomata are inactive or less functional over abroad range of weather conditions and for a longer time than those of most other plant species. Studies by Forsyth and Hall (1967) and Stang and Struckmeyer (1985) have implied this possibility, given the slow linear increase in photosynthesis observed across the 3.5 to $25 \mathrm{C}$ temperature range. Eck (1990) has proposed that there is an optimum leaf temperature range of $\approx 15$ to $\approx 27 \mathrm{C}$ for cranberry growth (although at the higher end of the range, damage has been observed).

Observations made on clear days and during midday and afternoon apparently provide the most meaningful information on cranberry $\mathrm{SC}$ and likely would provide clues to understanding cranberry physiology and improving plant water management. However, since observations were made during fruit maturation, when berries are the sink for metabolic activity, the stomatal response may have been modulating according to the fruiting needs of the plant. Abdallah and Palta (1989) have reported respiration to be highest during the green stage of fruit development, with a decline thereafter. With these considerations, further study would be appropriate according to cranberry phenophase across various
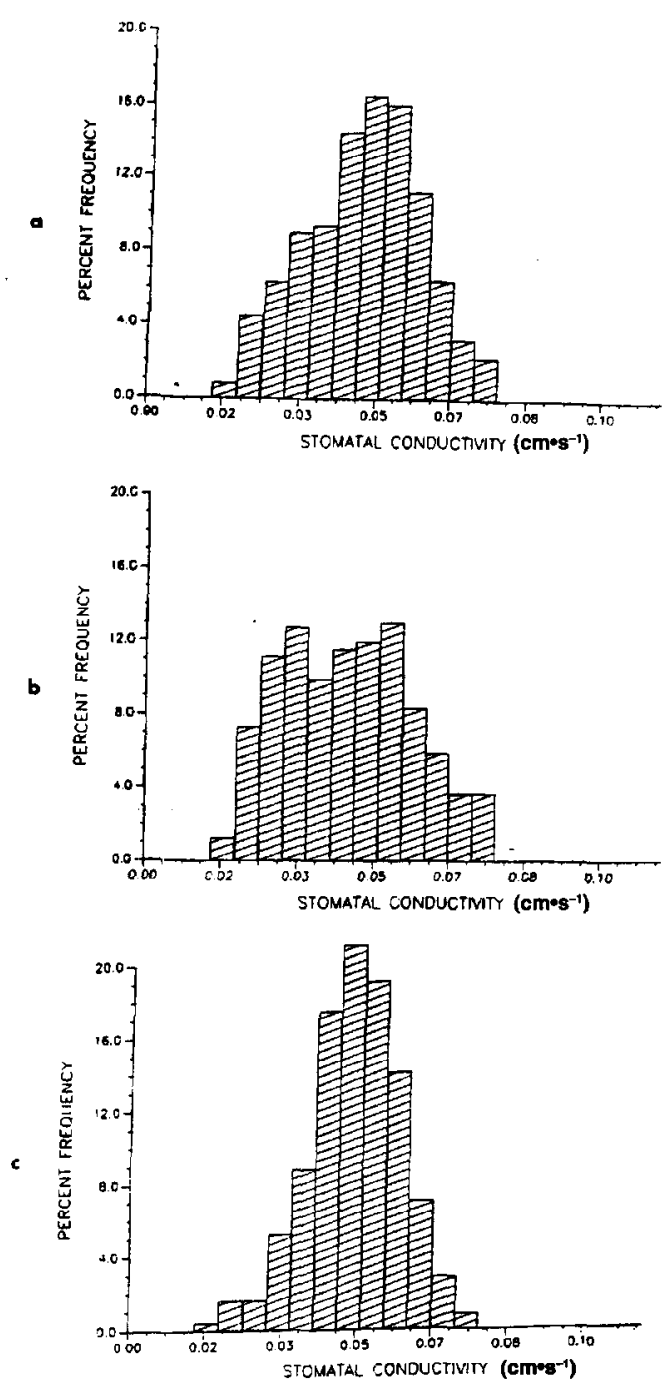

Fig. 2. Histograms of stomatal conductivity for (a) all days, (b) clear days, and (c) overcast days.

weather and field conditions or under a controlled greenhouse environment.

\section{Literature Cited}

Abdallah, A.Y. and J.P. Palta. 1989. Changes in biophysics and biochemical properties of cranberry fruit during growth and development. Acta Hort. 4th Intl. Symp. Vaccinium Cult., Lansing, Mich., 13-17 Aug. 1988. p. 360-365.

Avissar, R. 1993. Observations of leaf stomatal conductance at the canopy scale An atmospheric modeling perspective. Boundary Layer Meteorol. 64:127-148.

Eck, P. 1990. The American cranberry. Rutgers Univ. Press, New Brunswick, N.J.

Faraq, K.M. and A.Y. Palta. 1989. Ultrastructure and surface morphology of cranberry plant with reference to ethrel penetration. Acta Hort. 4th Intl. Symp. Vaccinium Cult., Lansing, Mich., 13-17 Aug. 1988. p. 378-384.

Forsyth, F.R. and I.V. Hall. 1967. Rates of photosynthesis and respiration in leaves of the cranberry with emphasis on rates at low temperatures. Can. J. Plant Sci. 47:19-23.

Holmgren, P., P.G. Jarvis, and M.S. Jarvis. 1965. Resistances to carbon dioxide and water vapour transfer in leaves of different plant species. Physiol. Plant. 18:557-573.
Idso, S.B., S.G. Allen, and B.J. Choudhury. 1988. Problems with porometry: Measuring stomatal conductance of potentially transpiring plants. Agr. Meteorol. 43:49-58.

Meyer, W.S., D.C. Reicosky, and N.L. Schaefer. 1985. Errors infield measurement of leaf diffusive conductance associated with leaf temperature. Agr. Meteorol. 36:55-64.

Monteith, J.L. 1990. Porometry and baseline analysis: The case for compatibility. Agr. Meteorol. 49:155-167.

Rochette, P., E. Pattey, R.L. Desjardins, L.M. Dwyer, D.W. Stewart, and P.A. Dube. 1991. Estimation of maize (Zea mays L.) canopy conductance by scaling up leaf stomatal conductance. Agr. Meteorol. 54:241-261.

Sawyer, W.H. 1932. Stomatal apparatus of the cultivated cranberry, Vaccinium macrocarpon. Amer. J. Bot. XIX:508-513.

Stang, E.J. and B.E. Sruckmeyer. 1985. Effect of four light levels on net photosynthesis and leaf anatomy of cranberry. Acta Hort. 3rd Intl. Symp. Vaccinium Cult., Warsaw, Poland, 24-28 July 1984. p. $325-333$

Turner, N.C. 1991. Measurement and influence of environmental and plant factors on stomatal conductance in the field. Agr. Meteorol. 54:137154. 